\title{
Aflatoxin and the acute aflatoxicosis outbreaks in Kenya: A review
}

\author{
${ }^{1}$ Njapau, H. and ${ }^{2}$ Lewis, L.L. \\ 1 U.S. Food and Drug Administration, Center for Food Safety and Applied Nutrition \\ Office of Regulatory Science, Division of Bioanalytical Chemistry \\ (College Park, Maryland, USA)
}

2 U.S. Centers for Disease Control and Prevention, National Center for Environmental Health, Division of Environmental Hazards and Health Effects, Health Studies Branch

(Chamblee, Georgia, USA)

\begin{abstract}
Acute aflatoxicosis outbreaks sporadically occur among subsistence farmers in Makueni and Kitui districts, Eastern Province, Kenya. Over the past 25 years, four documented outbreaks of acute aflatoxicosis affecting 467 individuals and resulting in 178 deaths have occurred in the same region. The outbreaks occurred in the southeastern part of Eastern Province between the months of April and July. The outbreaks resulted from the consumption of aflatoxin contaminated homegrown maize. Analysis of homestead and market maize samples collected from the affected region showed widespread contamination with aflatoxin at concentrations above 20 $\mu \mathrm{g} / \mathrm{kg}$. Approximately $18 \%$ of the samples were contaminated with aflatoxin at concentrations above $1,000 \mu \mathrm{g} / \mathrm{kg}$. Consumption of the contaminated maize (once or multiple times) could have resulted in estimated mean aflatoxin ingestion of 50 to $2,500 \mathrm{ng} / \mathrm{kg}$ bw/day, with a few individuals probably ingesting as high as $18,000 \mathrm{ng}$ aflatoxin $/ \mathrm{kg}$ bw/day. The exact cause of the aflatoxin contamination of the maize crop in this specific region has not been fully established. Circumstantial evidence suggests that weather and agricultural practices may have created favorable conditions for the proliferation of a prevalent and highly aflatoxigenic Aspergillus strain in the maize crop resulting in the production of high levels of aflatoxin in the harvested maize.
\end{abstract}

Key words: aflatoxin, maize, aflatoxicosis, outbreak, Kenya

\section{Introduction}

The aflatoxins (aflatoxin) are a highly toxic group of mycotoxins primarily produced by Aspergillus flavus and Aspergillus parasiticus ${ }^{1)}$. Aflatoxins frequently contaminate agricultural commodities in the field as well as during storage as a result of favorable environmental conditions, such as high humidity and temperature, and inappropriate storage. In affluent nations, regulatory measures help to ensure that contaminated commodities are destroyed or diverted to lower-risk uses. In economically challenged nations however, foodstuffs cannot simply be discarded, particularly when food supplies are limited. Over the last 40 years, significant progress has been made in understanding the biochemistry of aflatoxin formation as well as the environmental conditions that can lead to the production of aflatoxin in 
foodstuffs. Despite this, aflatoxin contamination of food commodities continues to pose a risk to human health worldwide.

Illnesses caused by aflatoxin may be particularly prevalent in tropical and subtropical regions where contamination of foodstuffs is widespread. The extent to which chronic exposure to aflatoxin contributes to the general poor health of many tropical inhabitants has not been fully ascertained. However, since the occurrence of a fatal disease affecting Turkey poults on English farms in 1960 that led to the discovery of aflatoxin ${ }^{2,3)}$, acute human intoxication from suspected aflatoxin consumption has been reported in Taiwan ${ }^{4)}$, Uganda ${ }^{5}$, and India ${ }^{6}$.

\section{Aflatoxin contamination of foodstuff in Kenya}

Kenya is a country on the east coast of Africa that sits astride the equator between latitudes $6^{\circ} \mathrm{N}$ and $4^{\circ} \mathrm{S}$ and longitudes $34^{\circ} \mathrm{E}$ and $42^{\circ} \mathrm{E}$ (Fig. 1). It is approximately $582,000 \mathrm{~km}^{2}$ in size and has several agro-climatic zones, with temperature and rainfall varying from $<5{ }^{\circ} \mathrm{C}$ to $>25^{\circ} \mathrm{C}$ and $150 \mathrm{~mm}$ to $1100 \mathrm{~mm}$, respectively ${ }^{7,8)}$. Agriculture is a source of livelihood for a majority $(75 \%)$ of the approximately 34 million inhabitants ${ }^{9)}$, and maize is the staple food cereal largely consumed in the form of Ugali (a thick dough or porridge also called Nsima or Nsadza in some localities in central and southern Africa).

The recent aflatoxicosis outbreaks occurred primarily in the southern region of Eastern Province, an area encompassing Kitui, Machakos and Makueni districts. The approximately $35,000 \mathrm{~km}^{2}$ (Fig.1) region is home to about 1.6 million inhabitants, mostly of the Akamba ethnic group. It is a semi-arid marginal mixed farming area that receives rainfall in a bimodal pattern designated as long and short rains ${ }^{8,10)}$. Whereas the long rains (March to August) season accounts for $80 \%$ of the annual national maize output, the short rains season (October to January) is the major maize production season in the marginal drought-prone area where the outbreaks occur ${ }^{11)}$.

The earliest reports of human exposure to aflatoxin in Kenya resulted from studies that assessed both exposure to aflatoxin and the incidence of primary liver cancer (hepatocellular carcinoma). In 1973, it was demonstrated that there was a variation in the mean aflatoxin contamination of human food in three regions of Murang'a district in Kenya's Central Province ${ }^{12)}$. Inhabitants of the study area were reported to have been consuming $242-1,073$ ng aflatoxin per day. Subsequently, other investigators demonstrated the presence of the aflatoxin $\mathrm{B}_{1}$-DNA adduct, 8,9-dihydro-8-(7"'-guanyl)-9-hydroxyaflatoxin (AFB-Gua) in urine from individuals living in Murang'a, Machakos and Makueni districts ${ }^{13-16)}$. By assuming equivalent excretion rates between rats and humans, Autrup and coworkers ${ }^{14)}$ estimated the aflatoxin intake to be $36-3,600 \mathrm{ng}$ aflatoxin/day. Further investigations at a local hospital in Embu, Eastern Province, Kenya, showed the presence of aflatoxin in the liver of living individuals, postmortem hepatocellular carcinoma specimens, and in the blood and urine of cirrhosis patient $^{17)}$. Aflatoxin was also found in the sera of kwashiokor and marasmic children, and in prenatal, cord, and maternal blood samples ${ }^{18,19)}$.

Aflatoxin has also been found in commercial foodstuffs marketed in Kenya's urban and peri-urban areas. In 1995 the presence of aflatoxin in processed maize flour from the Nairobi area was reported ${ }^{20)}$. In $2004,29 \%$ of samples of maize and mixed cereals flour used for weaning babies collected from the Kisumu district in Nyanza Province were shown to be contaminated $(2-82 \mu \mathrm{g} / \mathrm{kg})$ by aflatoxin ${ }^{21)}$.

\section{Analysis of maize from the 2004 outbreak for aflatoxin}

During the early stages of the 2004 outbreak, preliminary analysis of a few samples of maize from the affected districts using thin layer chromatography (TLC) provided an indication 


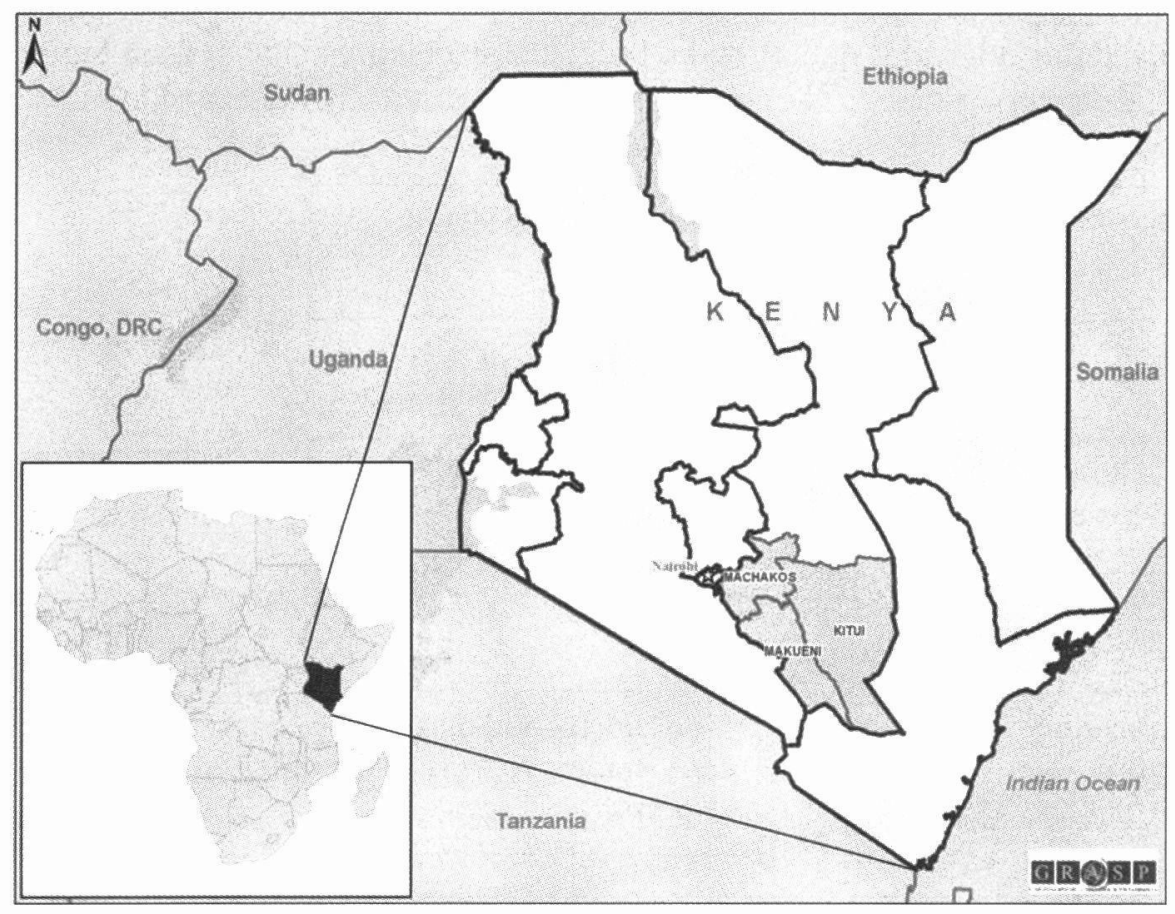

Fig. 1. Map of Africa showing relative position of Kenya and map of Kenya showing location of the aflatoxicosis outbreaks region (shaded) within Kenya. Courtesy: Carlos Bell (CDC).

of a high frequency of aflatoxin contamination at extremely high levels. Consequently, local authorities recognized the need for an analytical tool with a high sample throughput to quickly comprehend the magnitude and prevalence of the aflatoxin contamination in order to prioritize food replacement activities and thus reduce further loss of human life. Whenever the need for immediate analytical results occurs in a resource-poor community, the analytical tool of choice must be inexpensive, yet, simple, rugged and adaptable, in addition to being of proven performance (i.e., in addition to being affordable, it must be 'fit-for-purpose'). It was determined that the Vicam Immunoaffinity Fluorometric assay technique ${ }^{22,23)}$ was best suited for the conditions prevailing during both the existing outbreak and for potential future needs likely to be encountered in the field in Kenya.

\section{Assembly-Line Laboratory Operation}

In addition to the availability of a rapid analytical method, an analytical facility ('laboratory') configured to operate in an 'assembly-line' mode in order to attain the desired sample throughput was also needed. The configuration of the needed improvised 'laboratory' was comprised of multiple stations to carry out sample preparation and sample analysis. The sample preparation section included a course grinding station using hand grinders or handmills (Machakos, Kenya), a fine grinding station equipped with a Romer Grinding/Subsampling Mill (Series II, Romer Labs, Union, MO), and a weighing station. Coarsely ground samples of maize kernels were further ground to a fine texture using the Romer Mill. The finely-ground samples were passed on to the weighing station where analytical portions were removed and weighed. 
The sample analysis section consisted of a blending station, a filtration and dilution station, an affinity chromatography station, and a fluorometric determination (Vicam Series 4 Fluorometer) and data entry station. The configuration is schematically illustrated in Fig. 2.

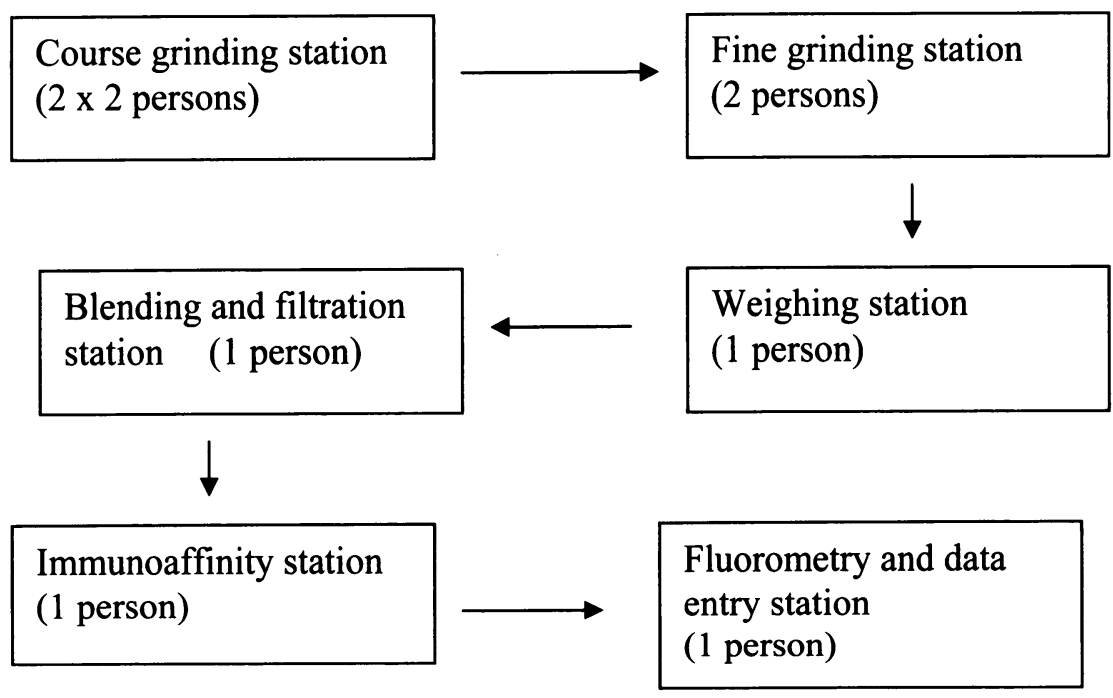

Fig. 2. A schematic of the assembly-line format analytical facility set-up utilized during the 2004 aflatoxicosis outbreak in Kenya.

\section{Aflatoxin content of maize from the $\mathbf{2 0 0 4}$ aflatoxicosis outbreak}

Three separate but complimentary investigations were carried out during the 2004 outbreak: a descriptive epidemiologic investigation, an analytical epidemiology (case-control) study, and a cross-sectional survey of commercial maize available in the general outbreak area. The cross-sectional survey ${ }^{24)}$ involved collecting maize samples from area markets and vendors whereas the descriptive and analytical epidemiology investigations involved collecting maize samples only from identified case-patient and matching control-households' stores ${ }^{25}$. Case-patient-households (case-households) were described as those households where a living or deceased member had developed acute jaundice of unknown origin leading to hospitalization during the peak of the outbreak. Control households were households from the same village as case-patients but with no reported occurrence of jaundice within the household during the outbreak period. Furthermore, maize samples were only collected from the respective case- and control-households if the household representative stated that the maize they had in storage at the time of sampling was part of a larger lot that they had a month before the onset of the outbreak. Thus, samples collected as part of the case-control investigation represented maize most probably consumed by individuals that developed jaundice, whereas samples collected as part of the cross-sectional survey represented maize that was generally available in the outbreak area and that may or may not have been consumed by outbreak victims.

The aflatoxin contamination of maize samples and incidences of aflatoxicosis in various localities of the outbreak area have been previously reported ${ }^{24-26)}$. The reports showed that $83 \%$ of the aflatoxicosis cases were clustered in two of the four districts in which the outbreak occurred. Table 1 shows a summary of the aflatoxin contamination data grouped according to the previously determined high aflatoxicosis incidence (Makueni/Kitui) and low aflatoxicosis incidence (Machakos/Thika) regions of the outbreak area. The table also shows the data classified according to aflatoxin contamination level categories that were arbitrarily determined, 
except for $>20 \mu \mathrm{g} / \mathrm{kg}$ category which is the official violative level of the government of Kenya. Overall, $68 \%$ and $43 \%$ of the maize samples from Makueni/Kitui and Machakos/Thika, respectively, were contaminated with aflatoxin above $20 \mu \mathrm{g} / \mathrm{kg}$. Aflatoxin contamination ranged from non-detectable to $25,000 \mu \mathrm{g} / \mathrm{kg}$ in maize samples from the Makueni/Kitui region and from non-detectable to $3,800 \mu \mathrm{g} / \mathrm{kg}$ in maize samples from the Machakos/Thika region. When the incidence of aflatoxin contamination is corrected for the difference in the number of samples analyzed per region, maize from the Makueni/Kitui region was approximately 40 times more likely to be contaminated above $1,000 \mu \mathrm{g} / \mathrm{kg}$.

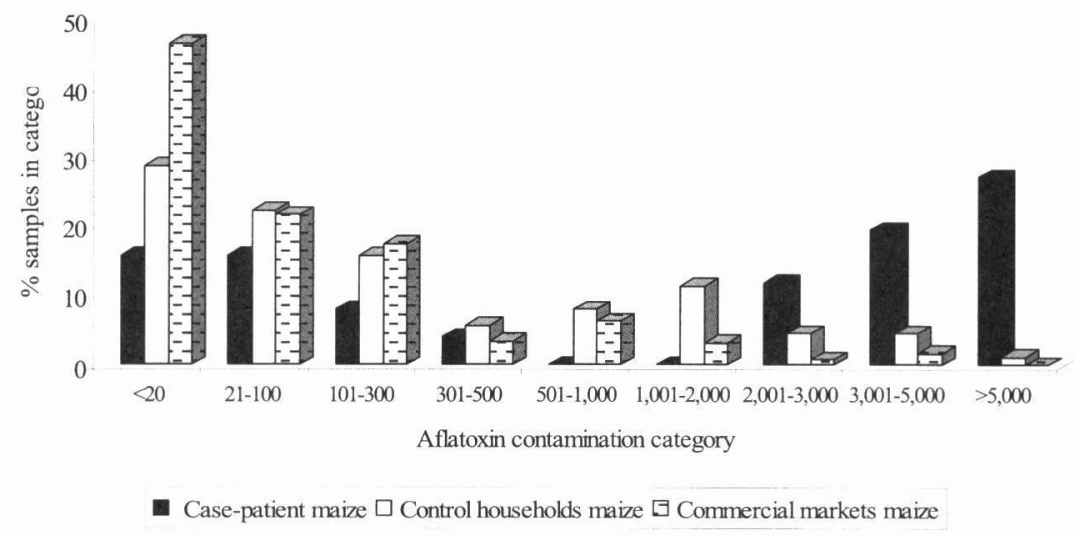

Fig. 3. Prevalence of aflatoxin contamination of maize samples from the 2004 aflatoxicosis outbreak.

Fig. 3 shows the prevalence of aflatoxin contamination in maize from case-households, control-households, and commercial markets in the general outbreak area. Each bar represents the percentage of samples with aflatoxin levels that fell within the specified aflatoxin contamination category. The percentage of case-households maize samples contaminated at $500 \mu \mathrm{g} / \mathrm{kg}$ or lower was either less or equivalent to that of samples from control-households and commercial markets. Above $2,000 \mu \mathrm{g} / \mathrm{kg}$, however, a substantial difference in contamination prevalence among the three different sources is evident. For example, close to $30 \%$ of the maize samples from case-patient households contained aflatoxin at above $5,000 \mu \mathrm{g} / \mathrm{kg}$ compared to $\leq 1 \%$ of maize samples from control-households and commercial markets.

\section{Aflatoxin and acute jandice}

There is no definitive diagnostic test for aflatoxin poisoning; it has primarily been a diagnosis of exclusion. Overwhelming evidence from recent and past aflatoxicosis outbreaks suggests a causal association between aflatoxin consumption, and acute and fatal hepatotoxic symptoms. In 2004, the most severe aflatoxicosis outbreak worldwide occurred in the Eastern Province of Kenya. The outbreak affected about 340 individuals resulting in 125 fatalities ${ }^{24,26)}$. Evidence that the 2004 outbreak could have resulted from foodborne aflatoxin poisoning included high levels of aflatoxin (up to $20,000 \mu \mathrm{g} / \mathrm{kg}$ ) detected in maize samples collected from case-households, a clinical illness consistent with aflatoxin poisoning, instances of clustering of cases, and a positive correlation between the occurrence of acute jaundice and levels of aflatoxin in maize samples from case-patient households ${ }^{25,27-29)}$. In addition, a correlation was shown between aflatoxin contamination and the number of aflatoxicosis cases in specific localities of the 2004 outbreak area ${ }^{24)}$. Aflatoxin contamination and aflatoxicosis were shown to be more prevalent in the southeastern region of Kitui and Makueni districts. Furthermore, screening for a panel of several potentially causative viruses that affect liver function yielded 


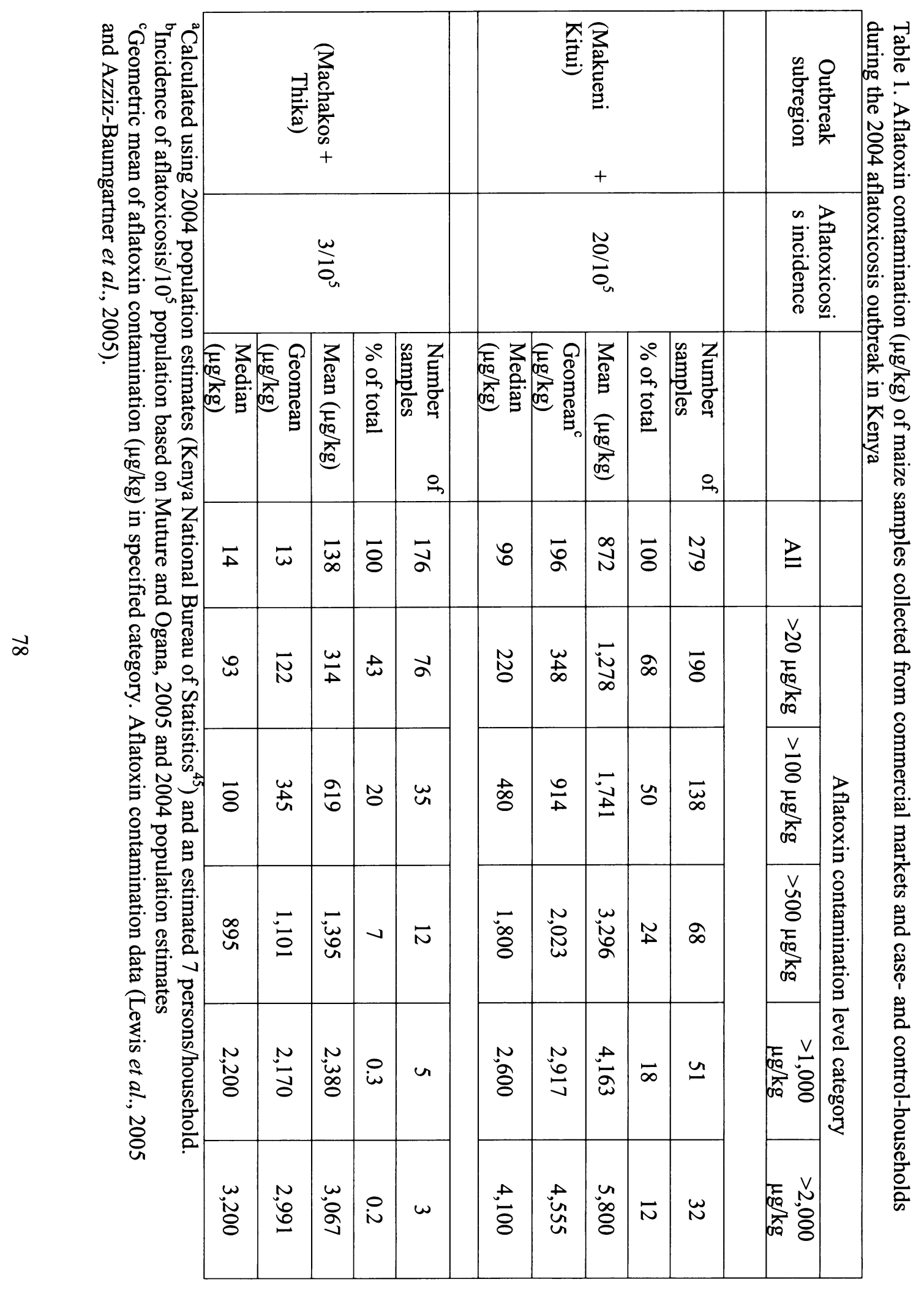


negative results except for hepatitis B where $44 \%$ of the case-patients and $7 \%$ of controls had positive titers ${ }^{25}$.

The 2004 aflatoxicosis outbreak was preceded by other food poisoning episodes in the Eastern and Central Provinces of Kenya that were reported to have been caused by consumption of aflatoxin-contaminated maize. An outbreak of jaundice involving 20 cases with 12 fatalities occurred in the Machakos district between March and June $1981^{30}$ ). Family clusters accounted for $80 \%$ of the cases and $83 \%$ of the fatalities. Most of the cases had been referred from two hospitals in present day Makueni district. Maize collected from granaries belonging to two families accounting for eight of the 12 deaths is reported to have contained $4,800-14,700 \mu \mathrm{g} / \mathrm{kg}$ aflatoxin whereas maize from unaffected households in the same area contained a maximum of $500 \mu \mathrm{g} / \mathrm{kg}$ aflatoxin. It was also reported that virological investigations of patients and asymptomatic neighbors were largely negative for known causal viral agents ${ }^{30)}$. In 2001 , local Kenyan media reports indicated that 24 individuals admitted to a hospital in Meru North district, Eastern Province, in or about August of that year, were suspected to have been exposed to high levels of aflatoxin ${ }^{31)}$. By early October, $12(50 \%)$ patients had died.

Following the 2004 outbreak, 76 and 51 cases of aflatoxicosis resulting in 32 and 21 fatalities were reported in Kitui and Makueni districts between April and June in 2005 and 2006, respectively $^{32)}$. In 2005, close to 300 maize samples were collected from households in Kitui and Makueni districts. Aflatoxin contamination ranged from non-detectable to $33,000 \mu \mathrm{g} / \mathrm{kg}$, and approximately $40 \%$ and $6 \%$ of the samples contained aflatoxin above $20 \mu \mathrm{g} / \mathrm{kg}$ and 1,000 $\mu \mathrm{g} / \mathrm{kg}$, respectively. In 2006 , approximately $50 \%$ and $9 \%$ of 165 maize samples collected from households in Kitui and Makueni districts were contaminated above $20 \mu \mathrm{g} / \mathrm{kg}$ and 1,000 $\mu \mathrm{g} / \mathrm{kg}$, respectively.

In summary, all of the aflatoxin poisoning episodes that have occurred in Kenya, except for that reported in 2001, occurred between April and July primarily in Makueni and Kitui districts.

Episodes of aflatoxin-consumption related foodborne poisoning have been reported elsewhere. In an aflatoxicosis outbreak in Taiwan, acute human intoxication was reported among 26 members of three families and resulted in three deaths ${ }^{4}$. Moldy rice from the affected homes was reported to contain about $200 \mu \mathrm{g} / \mathrm{kg}$ aflatoxin. In Uganda, the death of a 15-year old boy was associated with the consumption of cassava containing $1,700 \mu \mathrm{g} / \mathrm{kg}$ aflatoxin ${ }^{5)}$. Two siblings of the deceased boy were also reported to have been taken ill with symptoms of abdominal pain from which they recovered. In an outbreak that occurred in adjacent areas of Gujarat and Rajasthan, India, in 1974, 397 cases of jaundice resulting in 106 deaths were reported in a community where maize was the staple food ${ }^{6)}$. Aflatoxin consumption among affected individuals was estimated to be $2,000-6,000 \mu \mathrm{g}$ /day.

\section{Probable daily intake of aflatoxin during the 2004 outbreak}

The per capita maize consumption in the specific region of Kenya where the aflatoxicosis outbreaks occurred is unknown. However, information available elsewhere provides estimates of per capita maize consumption at the national level. The FAO database FAOSTAT shows that for the period 1990 to 2005, the Kenyan population consumed an average of $248 \mathrm{~g}$ maize per day ${ }^{33)}$. In a study in 1995, investigators estimated the per capita consumption of maize by the Kenyan population to be 400 grams $^{20)}$. It is generally acknowledged that consumption of a staple food such as maize is likely to be higher among rural communities, where alternative sources of nourishment are limited, than among urban dwellers. Hence, the 1995 per capita consumption estimate may more closely reflect that of rural communities such as the 2004 aflatoxicosis outbreak region. Although estimates of exposure to a foodborne contaminant are most appropriately computed from data collected over 
a period of time, such data are not usually available and is unlikely to be obtained during an outbreak. In this review, the combined commercial markets survey and case-control investigations data were used to estimate exposure based on the assumption that this data would represent the aflatoxin contamination of maize in the area during the outbreak. The derived single-point-based exposure data is crude but it provides an insight into the probable daily intake (PDI) of aflatoxin by communities in the outbreak area.

Table 2 shows crude estimates of overall PDI and probable isolated household clusters exposure represented by specific contamination categories. The PDI values were derived from the geometric mean contamination of a category, the conservative per capita maize consumption of $248 \mathrm{~g}$ and $60 \mathrm{~kg}$ mean adult weight ${ }^{34,35)}$. The geometric mean was used in computing the crude PDI estimates because, unlike the arithmetic mean, it is less affected by the presence, within a data set (or category), of a few extremely large figures, a common feature of aflatoxin contamination data. Table 2 also shows an exposure ratio (ER) and a prevalence ratio (PR). The exposure ratio shows the degree of exposure relative to an assumed 'safe baseline' exposure of $83 \mathrm{ng}$ aflatoxin/ $\mathrm{kg}$ bw/day derived from a daily consumption of $248 \mathrm{~g}$ maize contaminated at the official regulatory limit of $20 \mu \mathrm{g} / \mathrm{kg}$. The exposure ratio is, therefore, derived by dividing the calculated PDI by $83 \mathrm{ng} / \mathrm{kg}$ bw/day. The prevalence ratio represents the percentage of samples from a particular locality and within a specific category whose aflatoxin contamination level fell within the stated category.

Together, the two ratios provide an indication of the extent and impact of the estimated PDI within a locality. For instance, when all the results of a locality are pooled, the exposure ratio shows that inhabitants of Makueni and case-households may have ingested an average of 31 and 33 times more aflatoxin per day than would result from the permissible level of $20 \mu \mathrm{g} / \mathrm{kg}$. In contrast, residents of the Machakos/Thika region may seem to have been exposed to less than the permissible levels aflatoxin. It could therefore be surmised that the Machakos/Thika region should not have experienced an aflatoxicosis outbreak. The $>500 \mu \mathrm{g} / \mathrm{kg}$ and $>2,000 \mu \mathrm{g} / \mathrm{kg}$ categories show, however, that a small percentage $(2-7 \%)$ of the population in the Machakos/Thika region, perhaps localized clusters, may have potentially been exposed to 80-200-fold higher levels of aflatoxin per day.

The significance of the ER and PR ratios is illustrated by examining the $\geq 2,000 \mu \mathrm{g} / \mathrm{kg}$ aflatoxin contamination category in Table 2 . The estimated crude PDI for the Machakos/Thika region $(12,000 \mathrm{ng} / \mathrm{kg} \mathrm{bw} / \mathrm{day})$, is only about 1.5 times less than that of the Makueni/Kitui region $(19,000 \mathrm{ng} / \mathrm{kg}$ bw/day). However, the $\geq 2000 \mu \mathrm{g} / \mathrm{kg}$ aflatoxin category PR ratio for the Makueni/Kitui region is six times that of the Machakos/Thika region. Therefore, for households or individuals that could have been exposed to the levels of aflatoxin represented by the category, six times more inhabitants of the Makueni/Kitui region may have ingested 1.5 times more aflatoxin, probably contributing to the approximately seven times higher aflatoxicosis incidence. Among households where a family member was reported to have developed symptoms of jaundice, approximately $60 \%$ probably ingested close to $23,000 \mathrm{ng}$ aflatoxin $/ \mathrm{kg}$ bw/day compared to only $10 \%$ of control households that may have consumed an estimated 14,000 $\mathrm{ng} / \mathrm{kg}$ bw/day.

The investigations that yielded the data used in estimating probable daily intakes were retrospective in nature, thus weakening the apparent associations between aflatoxin consumption and acute or fatal jaundice that could be inferred from the data. Maize consumed by individuals that developed jaundice may have been different from the maize tested for aflatoxin. Hence, definitive conclusions about potential exposure thresholds above which aflatoxicosis symptoms may begin to manifest or fatalities may occur cannot be made. Furthermore, the general nutritional and health status of individuals exposed to aflatoxin may potentiate or mitigate the effects of the toxic insult. Disease or nutritional states that negatively affect liver function, hence its ability to detoxify aflatoxin, are likely to increase the 


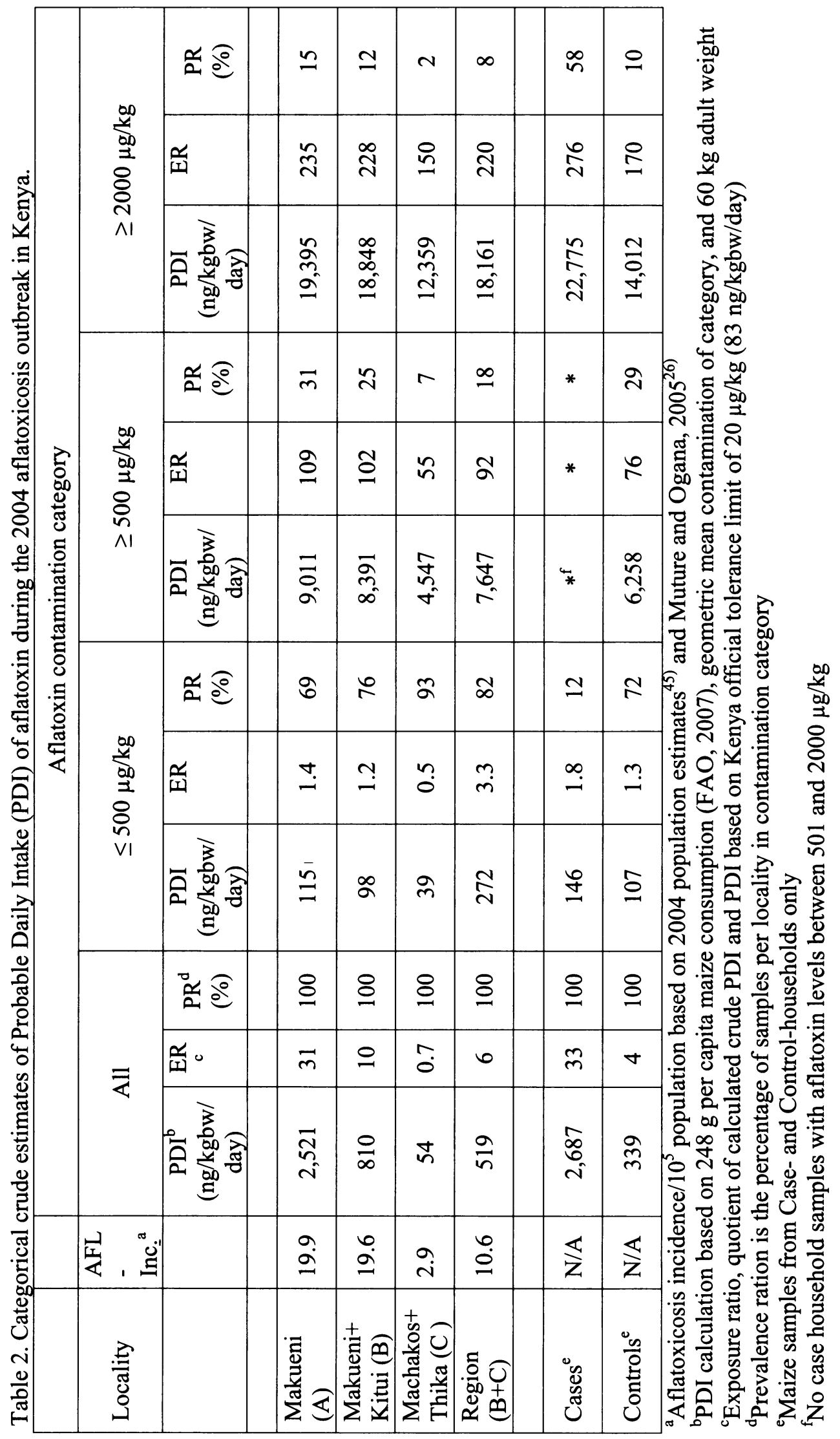


bioavailability of the toxin leading to adverse effects. For instance, infection with hepatitis B virus exacerbates the development of hepatocellular carcinoma associated with exposure to aflatoxin $^{36)}$. Therefore, quantities of aflatoxin that may have very minimal health effects on well nourished and healthy individuals may be fatal to those living under conditions of marginal nutrition and health. For instance, a laboratory technician in the USA is reported to have ingested $39,000 \mathrm{ng} / \mathrm{kg}$ bw/day and 36,000 $\mathrm{ng} / \mathrm{kg}$ bw/day aflatoxin $B_{1}$ over 2 and 14 day periods, respectively, in a suicide attempt but did not develop any serious illness other than transient nausea and headache ${ }^{37)}$. It has further been stated that the acute, lethal aflatoxin range for adult humans could be of the order of $170,000-330,000 \mathrm{ng} / \mathrm{kg} \mathrm{bw} / \mathrm{day}{ }^{1)}$. These exposure levels are well above those estimated for the highest category from the investigations of the outbreaks in Kenya.

\section{An aflatoxicosis outbreak trigger hypothesis}

The hypothesis presented here is based on the assumption that aflatoxin is the primary cause of the episodes of fatal jaundice that have occurred in the southeastern region of Kenya's Eastern Province over the years. For decades, maize has been widely grown and consumed in the region where the outbreaks have occurred, in other parts of Kenya, and in other countries in eastern and southern Africa ${ }^{33)}$. Furthermore, there is no indication that food consumption or storage practices in the region where outbreaks have occurred have changed in recent years. Intuitively therefore, it may be surmised that specific events occurred during the outbreak years that triggered the excessive contamination of the maize by aflatoxin.

Aspergillus flavus, the major producer of aflatoxin in maize, is ubiquitous and the conditions and agricultural practices that predispose maize to Aspergillus infection and subsequent aflatoxin production commonly occur in tropical and subtropical environments similar to those of the region where outbreaks recur. Indeed, investigations of the 2004 outbreak have shown that $98 \%$ of maize samples collected from that area were infected with Aspergillus flavus ${ }^{38)}$. More importantly, it was demonstrated that $73 \%$ of the Aspergillus flavus isolates belonged to the extremely toxigenic $\mathrm{S}$ strain.

Furthermore, it has been shown that about $50-80 \%$ of the maize collected from case-patients homes during the 2004 outbreak was insufficiently dried and improperly stored, i.e., the maize was stored wet and inside homes, perhaps a result of abnormal weather and food insecurity ${ }^{25}$ 28). Food insecurity and poverty in the outbreaks area is a perennially recurring problem for an estimated $10-40 \%$ of the population because the region is semi-arid with infertile soils and erratic rains ${ }^{8,39,40)}$.

As mentioned earlier, the aflatoxicosis outbreaks in Kenya occurred during the short rains season; this is the major maize growing season in the outbreaks area. Maize grown during the short rains season is harvested during a small but relatively dry February-March window before the onset of the long rains season. In 2003, the short rains were insufficient and either extended into the harvesting season or were followed by an early onset of the long rains ${ }^{41}$. Consequently more than normal rain fell during the harvesting season.

The foregoing led to the hypothesis that the maize crop was probably stressed by the preceding drought, thus making it susceptible to fungal infection. Furthermore, harvesting the maize at higher than 'normal' moisture content and storing it in homes greatly reduced the rate of drying which facilitated Aspergillus proliferation and aflatoxin production. Households, either knowingly (owing to the lack of alternative food sources) or unknowingly, consumed the tainted maize leading to the manifestation of aflatoxicosis. It has not been ascertained however, whether similar meteorological patterns existed in all the other years when aflatoxicosis outbreaks occurred. 


\section{Future considerations}

Complete elimination of aflatoxin may not be achievable in the short term because Aspergillus flavus is ubiquitous. The human population in the affected area may therefore continue to be exposed to aflatoxin, and similar aflatoxicosis outbreaks could occur in the future. There are however, long term strategies that could minimize the occurrence of aflatoxin in the maize before harvesting and during storage. Such strategies need to be effective, acceptable to the local population, and sustainable. The strategies include an integrated approach encompassing increasing public awareness of the hazard of consuming foodstuffs highly contaminated with aflatoxin, educating local farmers and communities about appropriate agricultural and storage practices, monitoring and predictive modeling for potential aflatoxin contamination. Sustainability of these strategies will only be achieved through enhancing the local capacity to carry out the aforementioned activities. These recommendations are made with the realization that food safety is one among multiple national priority areas that need to be addressed by local authorities. In most developing countries, minimizing infectious diseases and fighting malaria may take precedence ${ }^{42,43)}$.

In the interim, efforts could be focused on developing maize drying techniques applicable at the village level and encouraging the use of storage structures that permit further drying of the maize after harvest while protecting the crop from damage by pests and rain. A recent study 44 has shown that the use of low technology postharvest measures by subsistence farmers could substantially lower exposure to aflatoxin.

\section{References}

1) Pitt, J.I.: Med. Mycol., 38, 17-22 (2000)

2) Blount, W.P. : Turkeys, 9, 52 (1961)

3) Asplin, F.D., Carnaghan, R.B.A. : Vet Rec., 73, 1215-1219(1961)

4) Pitt, J.I.:An Introduction to Mycotoxins. In: Mycotoxin Prevention and Control in Food Grains: eds. Semple, R.L., Frio, A.S., Hicks, P.A., Lozare, J.V.(1989), Food and Agriculture Organization, Rome Italy

5) Serck-Hanssen, A.: Arch. Envrin. Health, 20, 729-731(1970)

6) Krishnamachari, K.A.V.R., Bhat, R.V., Nagarajan, V., Tilak, T.B.G.: Lancet, 1061-1063(1975)

7) Kassam, A.H., van Velthuizen, H.T., Fischer, G.W., Shah, M.M.: Agro-Ecological Land Resource Assessment for Agricultural Development Planning: A Case Study of Kenya Resources Data Base and Land Productivity(1993) Technical Annex 6. Food and Agriculture Organization, Rome Italy

8) Orodho, A.B.: Kenya: Country Pasture/Forage Resource Profiles (2006) Food and Agriculture Organization, Rome Italy http://www.fao.org/ag/agp/agpc/doc/counprof/kenya.htm

9) HDR:Beyond Scarcity: Power, Poverty and the Global Water Crisis, Human Development Index 2006(2006), United Nations Development Program, New York, NY http://www.hdr.undp.org/hdr2006/statistics/

10) KFSSG:Long Rains Assessment Report 2006, Consolidated Inter-Agency Report (2006) Kenya Food Security Steering Group, Nairobi, Kenya

11) Mutunga, N., Odour, J.: Kenya: July 2002-June 2003 Annual Harvest Assessment (2003) FEWSNET, Famine Early Warning Systems Network, USAID/Government of Kenya, Nairobi, Kenya. June 2003

12) Peers, F.G., Linsell, C.A.: Br. J. Cancer ,27, 473-484 (1973) 
13) Autrup, H., Bradley, K.A., Shamsuddin, A.K.M., Wakhisi, J., Wasunna, A.: Carcinogenesis, 4, 1193-1195

14) Autrup, H., Wakhisi, J., Vahakangas, K., Wasunna, A., Harris, C.C.: Environ. Health Perspect.,62, 105-108(1985)

15) Autrup, H.., Seremet, T., Wakhisi, J., Wasunna, A.: Cancer Res., 47, 3430-3433(1987)

16) Autrup, H., Wakhisi, J.: IARC Sci. Publ. 89, 63-66 (1988)

17) de Vries, H.R., Lamplugh, S.M. : Trop. Geogr. Med. 41, 26-30 (1989)

18) de Vries, H.R., Lamplugh, S.M. and Hendrickse, R.G.: Ann. Trop. Paediatr. , 7, 249-251(1987)

19) de Vries, H.R., Maxwell, S.M., Hendrickse, R.G.: Acta Paedatri. Scand. , 78, 373-378 (1989)

20) Muriuki, G.K., Siboe, G.M.: Afr. J. Health Sci., 2, 236-241(1995)

21) Okoth, S.O., Ohingo, M.: Afr. J. Health Sci., 11, 43-54(2004)

22) Trucksess, M.W., Stack, M.E., Nesheim, S., Page, S.W., Albert, R.H.: J. AOAC, 74, 81-88 (1991)

23) Vicam:Aflatest ${ }^{\circledR}$ procedure for corn grains and feeds (0-300 ppb). Doc. \#: GN-P1012-0 (1996) Vicam LP, Watertown, MA

24) Lewis, L., Onsongo, M., Njapau, H., Schurz-Rogers, H., Luber, G., Kieszak, S., Nyamongo, J., Backer, L., Dahiye, A.M., Misore, A., DeCock, K., Rubin, C.:Health Perspect., 113, 1763-1767(2005)

25) Azziz-Baumgartner, E. Lindblade, K., Gieseker, K., Schurz Rogers, H., Kieszak, S., Njapau, H., Schleicher, PR., McCoy, L.F. Misore, A., DeCock, K., Rubin, C., Slutsker, L.:Environ. Health Perspect., 113, 1779-1783(2005)

26) Muture, B., Ogana, G.: East Afr. Med J., 82, 275-279(2005)

27) EZtel, R.: JAMA, 287, 425-427(2002)

28) CDC:Outbreak of Aflatoxicosis Poisoning - Eastern and Central Provinces, Kenya, January-July, 2004, U.S. Centers for Disease Control and Prevention (2004) Weekly Morbidity and Mortality Reports (CDC-MMWR), September 3, 2004

29) Williams J.H., Phillips, T.D., Jolly, P.E., Stiles, J.K., Jolly, C.M. and Aggarwal, D. Am. J. Clin. Nutr. 80, 1106-1122 (2004)

30) Ngindu, A., Kenya, P.R., Ocheng, D.M., Omondi, T.N., Gatei, D., Johnson, B.K., Ngira, J.A., Nandwa, H., Jansen, A., Kaviti, J., Siongok, T.A.: Lancet, 1346-1348 (1982)

31) ProMED:Aflatoxicosis, Human - Kenya. ProMED -mail (2001) Program for Monitoring Emerging Diseases, International Society for Infectious Diseases http://www.promedmail.org

32) WHO:Kenya Situation Reports (2006) World Health Organization, Geneva, Switzerland http://www.who.int/hac/crises/ken/sitreps/2006/en/index.html.

33) FAOSTAT(2007) Food and Agriculture Organization, Rome, Italy http://faostat.fao.org/

34) AWDG:Australian Drinking Water Guidelines EH19, Chapter 6, National Health and Medical Research Council (2004) Government of Australia, 6-1 - 6-7 http://www.nhmrc.gov.au/publications/synopses/eh19syn.htm

35) van Liere, M.J., Ategbo, E-A.D., Hoorweg, J., den Hartog, A.P., Hautvast, G.A.J.: Br. J. Nutri., 72, 479-488(1994)

36) Henry, S.H., Bosch, F.X., Troxell, T.C., Bolger, P.M.: Science, 266, 2453-2454(1999)

37) Willis, R.M., Mulvihill, J.J., Hoofnagle, J.H.: Lancet , 1198-199 (1980)

38) Probst, C., Njapau, H., Cotty, P.J.: Appl. Environ. Microbiol., 73, 2762-2764(2007)

39) NHDR: Kenya National Human Development Report 2006 (2006) United Nations Development Program (UNDP), Nairobi, Kenya. www.ke.undp.org/06NHDRreport.pdf

40) Ndeng'e G.K., Opiyo, C., Mistiaen, J.A., Kristjanso, P.: Geographic Dimensions of Well-being in Kenya: Where are the Poor? From Districts to Locations, Vol 1. (2003) 
Kenya National Bureau of Statistics, Ministry of Planning and National Development, Kenya and World Dank Development Research Group, World Bank, Washington DC, USA. http://www.worldbank.org/reseach/povertymaps/kenya/volume_index.htm

41) FEWSNET: Kenya Food Security Report - July 7, 2004. Famine Early Warning Systems Network(2004) USAID/Government of Kenya, Nairobi, Kenya. www.fews.net/centers/files/kenya_200406en.pdf

42) Mulholland, E.K., Adegbola, R.A. : New Eng. J. Med. 352, 75-77 (2005)

43) UNICEF:Africa malaria Day 2007(2007) United Nations Children's Education Fund, New York, NY, http://www.unicef.org/media/media_39453.html

44) Turner, P.C., Sylla, A., Gong, Y.Y., Diallo, M.S., Sutcliffe, A.E., Hall, A.J. and Wild, C.P. Lancet 365, 1950-1956 (2005)

45) Kenya National Bureau of Statistics, Ministry of Planning and National Development, Kenya, Nairobi, Kenya 